\title{
In vitro Antioxidant, Membrane Stabilizing and Thrombolytic Activities of Glycosmis arborea
}

\author{
Sayed Mamur Hossain ${ }^{1}$, Farhana Islam ${ }^{2}$, Tasnuva Sharmin ${ }^{1}$, Hasib Sheikh ${ }^{1}$, A.M. Rashedul Hasan ${ }^{1}$ and \\ Mohammad A. Rashid ${ }^{2}$ \\ ${ }^{1}$ Department of Pharmacy, State University of Bangladesh, Dhaka-1205, Bangladesh \\ ${ }^{2}$ Department of Pharmaceutical Chemistry, Faculty of Pharmacy, University of Dhaka, Dhaka-1000, Bangladesh
}

\begin{abstract}
The methanol extract of leaves and stems of Glycosmis arborea and their pet-ether, carbon tetrachloride, chloroform and aqueous soluble partitionates were subjected to assays for antioxidant activity by Folin-Ciocalteau reagent, membrane stabilizing and thrombolytic activities. The carbon tetrachloride soluble fraction of stems of G. arborea demonstrated the presence of significant amount of phenolic compounds (36.95 $\pm 0.54 \mathrm{mg}$ of GAE/g of extract). The extractives inhibited heat as well as hypotonic solution-induced haemolysis of rat erythrocytes in vitro. The pet-ether soluble fraction of leaves and stems of G. arborea showed 20.46 and $38.24 \%$ and 22.50 and $48.25 \%$. inhibition of hemolysis of RBC caused by heat and hypotonic solution, as compared to 30.55 and $72.91 \%$ inhibition of hemolysis of RBC caused by the standard Acetyl salicylic acid at $0.01 \mathrm{mg} / \mathrm{ml}$ concentration, respectively. Among the four fractions, the chloroform soluble materials of the stems of $G$. arborea revealed highest thrombolytic activity with clot lysis value of $36.50 \%$ while standard streptokinase and water used as positive and negative controls, showed $64.25 \pm 0.26$ and $2.35 \pm 0.35 \%$ lysis of clot respectively
\end{abstract}

Key words: Glycosmis arborea, total phenolic content, antioxidant, membrane stabilization and thrombolysis

\section{Introduction}

Glycomis arborea Roxb. DC (Synonym- Glycosmis pentaphylla Retz. DC, Bengali name- Ashsaora, Kawatuti, Matmati, Ban Jamir) belongs to the family Rutaceae. The genus Glycosmis is represented by nearly 11 species. It is a shrub or small (1.5-5.0 m) tree widely distributed from India, Malaysia and Southern China to the Philippine Islands where it occurs in tropical forests at low altitudes (Wang et al., 2006). Traditionally it is used for the treatment of fever, liver complaints and certain other diseases. The stems are widely used as a brush for cleaning teeth (Quader et al., 1999).The plant is also used for cough, rheumatism, anemia and jaundice. Leaf juice is given with sugar in empty stomach in the morning to eradicate ascariasis, while the leaf paste mixed with ginger is used in eczema and skin infections. The leaf extract and crude alkaloids possess antibacterial and antifungal properties (Medicinal plants database of Bangladesh). As a part of our continuing studies of medicinal plants of Bangladesh (Kaisar et al., 2011; Kabir et al., 2010) the methanol extracts of leaves and stem of $G$. arborea growing in Bangladesh were screened for antioxidant activity in terms of total phenolic content as well as membrane stabilizing and thrombolytic activities for the first time and we, here in, report the results of our preliminary investigations.

\section{Materials and Methods}

Plant materials: The leaves and stems of G. arborea were collected from Dhaka and a voucher specimen (DUSH-5638) of the plant sample has been deposited in Department of Botany, University of Dhaka for future reference.

Extraction and fractionation: The collected plant parts were sun dried for several days and then oven dried for 24 hours at $40^{\circ} \mathrm{C}$ to facilitate grinding. The powdered leaves (450 gm) and stem (300 gm) were separately macerated in $1.5 \mathrm{~L}$ of methanol for 7 days and then filtered through a cotton plug followed by Whatman filter paper number 1 . The extracts were concentrated with a rotary evaporator at low temperature $\left(40-45^{\circ} \mathrm{C}\right)$ and reduced pressure. The concentrated methanol extracts were fractionated by the modified Kupchan partitioning protocol (Van Wagenen et al., 1993) and the resultant partitionates i.e., pet-ether (PESF), carbon tetrachloride (CTCSF), chloroform (CSF) and aqueous (AQSF) soluble fractions (Table 1) were used for the biological screenings. 
Table 1. Kupchan partitionates of leaves and stem of $G$. arborea obtained from $5 \mathrm{gm}$ of methanol extract

\begin{tabular}{lccc}
\hline Leaf extracts & $\begin{array}{c}\text { Amount } \\
\text { (gm) }\end{array}$ & Stem extracts & $\begin{array}{c}\text { Amount } \\
\text { (gm) }\end{array}$ \\
\hline ME & 5.0 & ME & 5.0 \\
PESF & 1.2 & PESF & 1.0 \\
CTCSF & 1.0 & CTCSF & 0.8 \\
CSF & 0.7 & CSF & 0.5 \\
AQSF & 0.5 & AQSF & 0.5 \\
\hline
\end{tabular}

Biological Investigation

(i) Total phenolic content: The total phenolic contents of the extractives were determined with Folin-Ciocalteau reagent by using the method developed by Harbertson and Spayd (2006). To $0.50 \mathrm{ml}$ of each sample (three replicates), $2.5 \mathrm{ml}$ of 1/10 dilution of Folin-Ciocalteau reagent and $2.0 \mathrm{ml}$ of sodium carbonate $(7.5 \%, \mathrm{w} / \mathrm{v})$ in water were added and incubated for $15 \mathrm{~min}$ at $45{ }^{\circ} \mathrm{C}$. The absorbance of all samples was measured at $765 \mathrm{~nm}$ with a visible spectrophotometer. The phenolic contents were expressed as milligrams of gallic acid equivalent per gram (mg GAE/g) of dry weight of extract.

(ii) Membrane stabilizing activity: The membrane stabilizing activity of the extractives was assessed by using hypotonic solution and heat-induced hemolysis of human erythrocyte by the method developed by Shindhe et al. 1999 with slight modification by Sikder et al. 2011 by using acetyl salicylic acid as standard.

(iii) Thrombolytic activity: The thrombolytic activity of all extractives was evaluated by the method developed by Prasad et al. 2006 using streptokinase (SK) as positive control.

Statistical Analysis: Three replicates of each sample were used for each assay to facilitate statistical analysis and the values are reported as mean \pm SD.

\section{Results and Discussion}

The crude methanol extracts of leaves and stems of $G$. arborea as well as different Kupchan partitionates derived from these extracts were subjected to assays for total phenolic content, membrane stabilizing and thrombolytic activities by following standard protocols. The total phenolic content in the samples were found in the range of $8.0 \pm 0.22$ to $36.95 \pm 0.54 \mathrm{mg}$ of GAE/g of sample. . In this study, the carbon tetrachloride soluble fraction of crude methanol extract of both the leaves and stems of $G$. arborea revealed the highest total phenolic content (18.08 \pm 0.32 and $36.95 \pm 0.54 \mathrm{mg}$ of $\mathrm{GAE} / \mathrm{g}$ of sample, respectively (Table 2).

The extractives of $G$. arborea at $2.0 \mathrm{mg} / \mathrm{mL}$ significantly protected the lysis of erythrocyte membrane induced by hypotonic solution and heat as compared to the standard, acetyl salicylic acid $(0.10 \mathrm{mg} / \mathrm{mL})$. In hypotonic solution induced conditions, the samples were found to inhibit lysis of erythrocyte membrane within the range of $21.42 \pm 0.24$ to $48.25 \pm 0.75 \%$. Among the samples, the pet-ether soluble fraction (PESF) of leaves and stems of G. arborea displayed high inhibition (38.24 \pm 0.26 and $48.25 \pm 0.75 \%$ ) hemolysis of RBC as compared to 72.91 $\pm 0.21 \%$ demonstrated by acetyl salicylic acid (Table 2).

Besides, in heat- induced conditions, the samples were found to inhibit lysis of erythrocyte membrane within the range of $12.55 \pm 0.22$ to $22.50 \pm 0.44 \%$. Here, the pet-ether soluble fraction (PESF) of leaves and stems of G. arborea inhibited maximum $20.46 \pm 0.54$ and 22.50 $\pm 0.44 \%$ hemolysis of RBC as compared to $30.55 \pm$ $0.55 \%$ demonstrated by acetyl salicylic acid (Table 2).

The extractives of G. arborea were also assessed for thrombolytic activity and the results are presented in Table 2. Addition of $100 \mu \mathrm{l} \mathrm{SK}$, a positive control (30,000 I.U.) to the clots of human blood and subsequent incubation for 90 minutes at $37^{\circ} \mathrm{C}$, showed $64.25 \%$ lysis of clot. On the other hand, distilled water when treated as negative control showed negligible percentages of lysis of clot $(2.35 \%)$. The mean difference in percentage of clot lysis between positive and negative control was found to be statistically significant. In this study, the chloroform soluble fraction of crude methanol extract of both the leaves and stems of $G$. arborea revealed highest thrombolytic activity (29.05 \pm 0.45 and $36.50 \pm 0.86 \%$, respectively) whereas the carbon tetrachloride and petether soluble materials from stems of $G$. arborea displayed moderate thrombolytic activities (31.68 \pm 0.54 and $28.95 \pm 0.33 \%$, respectively). 
Table 2. Total phenolic content, membrane stabilizing and thrombolytic activities of leaves and stems of G. arborea

\begin{tabular}{|c|c|c|c|c|}
\hline \multirow[t]{2}{*}{ Test samples } & \multirow{2}{*}{$\begin{array}{c}\text { Total phenolic content } \\
\text { (mg of gallic acid/gm } \\
\text { of extract) }\end{array}$} & \multicolumn{2}{|c|}{ Membrane stabilizing activity } & \multirow{2}{*}{$\begin{array}{c}\text { Thrombolytic activity } \\
\text { (\% clot lysis) }\end{array}$} \\
\hline & & $\begin{array}{l}\text { Heat induced } \\
\text { inhibition (\%) }\end{array}$ & $\begin{array}{l}\text { Hypotonic solution induced } \\
\text { inhibition (\%) }\end{array}$ & \\
\hline \multicolumn{5}{|c|}{ Leaf extractives } \\
\hline $\mathrm{ME}$ & $10.50 \pm 0.25$ & $16.25 \pm 0.61$ & $35.15 \pm 0.15$ & $20.55 \pm 0.82$ \\
\hline PESF & $14.94 \pm 0.65$ & $20.46 \pm 0.54$ & $38.24 \pm 0.26$ & $24.22 \pm 0.75$ \\
\hline CTCSF & $18.08 \pm 0.32$ & $19.58 \pm 0.45$ & $31.29 \pm 0.61$ & $27.65 \pm 0.25$ \\
\hline CSF & $11.68 \pm 0.22$ & $17.59 \pm 0.29$ & $30.33 \pm 0.68$ & $29.05 \pm 0.45$ \\
\hline AQSF & $8.0 \pm 0.22$ & $12.55 \pm 0.22$ & $21.42 \pm 0.24$ & $18.61 \pm 0.34$ \\
\hline \multicolumn{5}{|c|}{ Stem extractives } \\
\hline $\mathrm{ME}$ & $20.31 \pm 0.35$ & $18.20 \pm 0.28$ & $38.25 \pm 0.56$ & $24.26 \pm 0.25$ \\
\hline PESF & $30.20 \pm 0.61$ & $22.50 \pm 0.44$ & $48.25 \pm 0.75$ & $28.95 \pm 0.33$ \\
\hline CTCSF & $36.95 \pm 0.54$ & $21.65 \pm 0.61$ & $41.78 \pm 0.11$ & $31.68 \pm 0.54$ \\
\hline CSF & $24.34 \pm 0.26$ & $18.31 \pm 0.95$ & $35.26 \pm 0.38$ & $36.50 \pm 0.86$ \\
\hline AQSF & $10.15 \pm 0.88$ & $14.95 \pm 0.16$ & $30.55 \pm 0.64$ & $19.35 \pm 0.12$ \\
\hline ASA & - & $30.55 \pm 0.55$ & $72.91 \pm 0.21$ & - \\
\hline SK & - & - & - & $64.25 \pm 0.26$ \\
\hline Water & - & - & - & $2.35 \pm 0.35$ \\
\hline
\end{tabular}

$\mathrm{ME}=$ Methanolic crude extract; PESF $=$ Pet-ether soluble fraction of methanol extract CTCSF $=$ Carbon tetrachloride soluble fraction of methanol extract; CSF = Chloroform soluble fraction of methanol extract; AQSF = Aqueous soluble fraction of methanol extract; ASA= Acetyl salicylic acid; SK $=$ Streptokinase.

\section{References}

Harbertson, J. and Spayd, S. 2006. Measuring phenolics in the winery. Am. J. Enol. Vitic., 57, 280-288.

Prasad, S., Kashyap, R.S., Deopujari, J.Y., Purohit, H.J., Taori, G.M. and Daginawala, H.F. 2006. Development of in vitro model to study clot lysis activity of thrombolytic drugs. Throm. J., 4, 14

Quader, M.A., Nutan, M.T.H. and Rashid, M.A. 1999. Antitumor alkaloid from Glycosmis pentaphylla. Fitoterapia, 70, 305-307

Kabir, S., Rahman, M.S., Chowdhury, A.M., Hasan, C.M., and Rashid, M.A. 2010. An unusual bisnor-Clerodane diterpenoid from Polygonum simiarum. Nat. Prod. Commun.5, 1543-1546.

Kaisar, M.A., Rahman, M.S., Rahman, M.Z., Hasan, C.M. and Rashid, M.A. 2011. A review on phytochemicals from some medicinal plants of Bangladesh. J. Phar. Nutri. Sci., 1, 8795.
Medicinal plants database of Bangladesh; available online at: http://www.mpbd.info/plants/glycosmis-pentaphylla.php

Shindhe, U.A., Phadke, A.S., Nair, A.M., Mungantiwar, A.A., Dikshit, V.J. and Saraf, M.N. 1999. Membrane stabilizing activity - a possible mechanism of action for the antiinflammatory activity of Cedrus deodara wood oil. Fitoterapia,70, 251-257.

Sikder, M.A., Rahman, M.A., Kaisar, M.A., Rahman, M.S., Hasan, C.M. and Rashid, M.A. 2011. In vitro Antioxidant, Reducing Power, Free Radical Scavenging and Membrane stabilizing activities of seeds of Syzygium cumini L. Lat. Am. J. Pharm., 30, 781-785.

Van Wagenen, B.C., Larsen, R., Cardellina, J.H., Ran dazzo, D., Lidert, Z.C. and Swithenbank, C. 1993. Ulosantoin, a potent insecticide from the sponge Ulosa ruetzleri. J. Org. Chem., 58, 335-337.

Wang, J., Di, Y., Yang, X., Li, S., Wang, Y. and Hao, X. 2006. Hydroquinone diglycoside acyl esters from the stems of Glycosmis pentaphylla. Phytochemistry, 67, 486-491. 